\title{
Identification and characterization of Rhipicephalus (Boophilus) microplus candidate protective antigens for the control of cattle tick infestations
}

\author{
Consuelo Almazán • Rodolfo Lagunes • Margarita Villar • Mario Canales • \\ Rodrigo Rosario-Cruz • Frans Jongejan • José de la Fuente
}

Received: 11 August 2009 / Accepted: 10 November 2009/Published online: 27 November 2009

(C) The Author(s) 2009. This article is published with open access at Springerlink.com

\begin{abstract}
The cattle ticks, Rhipicephalus (Boophilus) spp., affect cattle production in tropical and subtropical regions of the world. Tick vaccines constitute a cost-effective and environmentally friendly alternative to tick control. The recombinant Rhipicephalus microplus Bm86 antigen has been shown to protect cattle against tick infestations. However, variable efficacy of Bm86-based vaccines against geographic tick strains has encouraged the research for additional tick-protective antigens. Herein, we describe the analysis of $R$. microplus glutathione-S transferase, ubiquitin (UBQ), selenoprotein $\mathrm{W}$, elongation factor-1 alpha, and subolesin (SUB) complementary DNAs (cDNAs) by RNA interference (RNAi) in R. microplus and Rhipicephalus annulatus. Candidate protective antigens were selected for
\end{abstract}

\section{Almazán}

Facultad de Medicina Veterinaria y Zootecnia,

Universidad Autónoma de Tamaulipas,

Km. 5 carretera Victoria-Mante,

CP 87000 Victoria, Tamaulipas, Mexico

\section{R. Lagunes}

Facultad de Medicina Veterinaria y Zootecnia,

Universidad Nacional Autónoma de México,

Avenida Universidad 3000,

CP 04510 Mexico, DF, Mexico

M. Villar $\cdot$ M. Canales $\cdot$ J. de la Fuente $(\triangle)$

Instituto de Investigación en Recursos Cinegéticos

IREC (CSIC-UCLM-JCCM),

Ronda de Toledo $\mathrm{s} / \mathrm{n}$,

13005 Ciudad Real, Spain

e-mail: jose_delafuente@yahoo.com

\section{R. Rosario-Cruz}

Centro Nacional de Investigación Disciplinaria en Parasitología

Veterinaria,

Carretera Federal Cuernavaca-Cuautla 8534, Col. Progreso,

Jiutepec, Morelos CP 62550, Mexico vaccination experiments based on the effect of gene knockdown on tick mortality, feeding, and fertility. Two cDNA clones encoding for UBQ and SUB were used for cattle vaccination and infestation with $R$. microplus and $R$. annulatus. Control groups were immunized with recombinant Bm86 or adjuvant/saline. The highest vaccine efficacy for the control of tick infestations was obtained for Bm86. Although with low immunogenic response, the results with the SUB vaccine encourage further investigations on the use of recombinant subolesin alone or in combination with other antigens for the control of cattle tick infestations. The UBQ peptide showed low immunogenicity, and the results of the vaccination trial were inconclusive to assess the protective efficacy of this

\footnotetext{
F. Jongejan

Utrecht Centre for Tick-borne Diseases (UCTD),

Department of Infectious Diseases and Immunology,

Faculty of Veterinary Medicine, Utrecht University,

Yalelaan 1,

3584CL Utrecht, The Netherlands
}

\author{
F. Jongejan \\ Department of Veterinary Tropical Diseases, \\ Faculty of Veterinary Science, \\ University of Pretoria, \\ Private Bag X04, \\ 0110 Onderstepoort, South Africa
}

\section{J. de la Fuente}

Department of Veterinary Pathobiology,

Center for Veterinary Health Sciences,

Oklahoma State University,

Stillwater, OK 74078, USA 
antigen. These experiments showed that RNAi could be used for the selection of candidate tick-protective antigens. However, vaccination trials are necessary to evaluate the effect of recombinant antigens in the control of tick infestations, a process that requires efficient recombinant protein production and formulation systems.

\section{Introduction}

Rhipicephalus (Boophilus) spp. ticks are distributed in tropical and subtropical regions of the world with range expansion for some species due to changes in climatic conditions (Barker and Murrell 2004; Estrada-Peña et al. 2006; Olwoch et al. 2007). Infestations with the cattle tick, Rhipicephalus microplus, economically impact cattle production by reducing weight gain and milk production, and by transmitting pathogens that cause babesiosis (Babesia bovis and Babesia bigemina) and anaplasmosis (Anaplasma marginale; Peter et al. 2005). Rhipicephalus annulatus is present in regions of Asia, Latin America, and Africa (Estrada-Peña et al. 2006) where it may also affect cattle production and transmit pathogens.

Acaricide application constitutes a major component of integrated tick control strategies (Graf et al. 2004). However, use of acaricides has had limited efficacy in reducing tick infestations and is often accompanied by serious drawbacks, including the selection of acaricideresistant ticks, environmental contamination, and contamination of milk and meat products with drug residues (Graf et al. 2004). All of these issues reinforce the need for alternative approaches to control tick infestations such as the use of hosts with natural resistance to ticks, pheromoneimpregnated decoys for attracting and killing ticks, biological control agents, and vaccines (de la Fuente and Kocan 2006; Sonenshine et al. 2006; Willadsen 2006).

In the early 1990s, vaccines inducing immunological protection on vertebrate hosts against tick infestations were developed and commercialized. The commercial vaccines, Gavac and TickGARD, contained the recombinant R. microplus Bm86 gut antigen (Willadsen et al. 1989; Rand et al. 1989; Rodríguez et al. 1994; de la Fuente and Kocan 2003; de la Fuente et al. 2007a). These vaccines reduce the number of engorging female ticks, their weight, and reproductive capacity. Thus, the greatest vaccine effect was the reduction of larval infestations in subsequent generations. Vaccine-controlled field trials in combination with acaricide treatments demonstrated that an integrated approach resulted in control of tick infestations while reducing the use of acaricides (de la Fuente et al. 1998, 2007a; de la Fuente and Kocan 2003). These trials demonstrated that control of ticks by vaccination has the advantages of being cost-effective, reducing environmental contamination, and preventing the selection of drug resistant ticks that result from repeated acaricide application. In addition, these vaccines may also prevent or reduce transmission of pathogens by reducing tick populations and/or affecting tick vector capacity (de la Fuente et al. 1998, 2007a; Rodríguez Valle et al. 2004).

Controlled immunization trials have shown that $R$. microplus Bm86-containing vaccines also protect against related tick species, $R$. annulatus and Rhipicephalus decoloratus (Fragoso et al. 1998; de la Fuente et al. 2000a; de Vos et al. 2001). However, R. microplus strain-to-strain variations in the susceptibility to $\mathrm{Bm} 86$ vaccination have been reported, and the efficacy of the Bm86 vaccine is higher against $R$. annulatus than against $R$. microplus strains, suggesting that tick genetic and/or physiological differences may affect the efficacy of tick vaccines in different regions (Fragoso et al. 1998; García-García et al. 1999; 2000; de la Fuente et al. 1999, 2000a, b; de Vos et al. 2001; de la Fuente and Kocan 2006; Sossai et al. 2005; Canales et al. 2009a). These results together with the need to improve vaccine efficacy have encouraged research for additional tick protective antigens for the control of cattle tick infestations (de la Fuente and Kocan 2003, 2006; Sonenshine et al. 2006; Willadsen 2006).

In the experiments reported herein, selected $R$. microplus complementary DNA (cDNA) sequences were characterized by RNA interference (RNAi) in unfed and replete adult ticks. Tick subolesin and ubiquitin were used for vaccination trials with recombinant proteins in cattle to evaluate their capacity to protect against cattle tick infestations.

\section{Materials and methods}

Tick strains The $R$. microplus (susceptible Media Joya strain, CENAPA, Mexico) and $R$. annulatus (Mercedes strain, Texas, USA) ticks were obtained from laboratory colonies maintained at the University of Tamaulipas, Mexico. Originally, these tick strains were collected from infested cattle in Tapalpa, Jalisco, Mexico and Mercedes County, Texas, USA for $R$. microplus and $R$. annulatus, respectively. Tick larvae were fed on cattle and collected after repletion to allow for oviposition and hatching in humidity chambers at $12 \mathrm{~h}$ light: $12 \mathrm{~h}$ dark photoperiod, 22 $25^{\circ} \mathrm{C}$, and $95 \%$ relative humidity (RH). Larvae were 15 days old at the time of infestations.

RNA interference in ticks Genes for RNAi were selected based on previous results in R. microplus or Dermacentor variabilis demonstrating the effect of gene knockdown on tick attachment, mortality, and/or fertility (de la Fuente et al. 2007b; 2008). These genes included those encoding for putative glutathione-S transferase (GST; GenBank acces- 
sion number AF077609), ubiquitin (UBQ; AA257892), selenoprotein W (SEL; tentative consensus sequence TC19044, http://compbio.dfci.harvard.edu/tgi/cgi-bin/tgi/ tc_report.pl?gudb=b_microplus\&tc $=\mathrm{TC} 19044)$, elongation factor-1 alpha (EF-1a; EU436163), and subolesin (SUB; DQ159966).

Oligonucleotide primers containing $\mathrm{T} 7$ promoter sequences at the 5'-end (GST: GSTBMT75: 5'- TAATACG ACTCACTATA GGGTACTCCATGGCTCCTGTGCTC GGCT-3' and GSTBMT73: 5'- TAATACGACTCACTATA GGGTACTCATTGAGAGGCCACTTAATGC-3'; UBQ: UB2BMT75: 5'-TAATACGACTCACTATAGGGTACT TTGGTCCTGCGGCTCCGCGGAG-3' and UB2BMT73: 5'-TAATACGACTCACTATAGGGTACTGCCACCACGG AGCCGCAGGACA-3'; SEL: SEBMT75: 5'-TAATAC GACTCACTATAGGGTACTCCACCGTGACTGGCACAG TAG-3' and SEBMT73: 5'-TAATACGACTCACTATAGGG TACTCCATACATGAATGGCTTTCCA-3'; EF-1a: GII5: 5'-TAATACGACTCACTATAGGGTACTGGCCCACGGAC AAACCCCTC-3' and GII3: 5'-TAATACGACTCACTATAG GGTACTCGACCGTTTGCCTCATGTC-3'; SUB: D8BMT75: 5'-TAATACGACTCACTATAGGGTACTGACT GGGACCCCTTGCACAGT-3' and D8BMT73 5'-TAATAC GACTCACTATAGGGTACTCGAGTTTGGTAGATAG CACA-3) were synthesized and used for in vitro transcription of double-stranded RNA (dsRNA) using the Access reverse transcription-polymerase chain reaction (RT-PCR) system (Promega, Madison, WI, USA) and the Megascript RNAi kit (Ambion, Austin, TX, USA) following manufacturer's instructions. The dsRNA was purified and quantified by spectrophotometry.

Newly molted $R$. microplus and $R$. annulatus females were injected with approximately $0.3 \mu \mathrm{l}$ of dsRNA $\left(5 \times 10^{10}\right.$ molecules per microliter) in the lower right quadrant of the ventral surface of the exoskeleton of the tick (Nijhof et al. 2007). Thirty ticks per group were injected using a Hamilton syringe with a 1-inch, 33-gauge needle. Control ticks were injected with the unrelated GIII dsRNA or were left uninjected. The GIII sequence was identified in $R$. microplus and did not affect tick feeding, mortality, and oviposition after RNAi (unpublished results). Ticks were held in a humidity chamber for $3-5 \mathrm{~h}$ before surviving ticks were allowed to feed in separate patches, each one for a different group, glued on the back of a calf. Ten males were placed in each patch simultaneously with injected females. Unattached ticks were removed 2 days after infestation, and attached ticks were allowed to feed until repletion. Engorged female ticks started to drop off the host after 8 days and were collected during 4 days. All the females completing feeding were counted and weighted. The average \pm standard deviation (SD) weights of engorged females were compared between test and control groups by Student's $t$ test $(P=0.05)$. Tick attachment was recorded with respect to surviving ticks after injection, and tick mortality was recorded with respect to the total number of attached ticks feeding on the animal and were compared between test and control groups by $\chi^{2}$ test $(\alpha=0.01)$. For oviposition, individual ticks were held in a humidity chamber at $22-25^{\circ} \mathrm{C}$ and $95 \% \mathrm{RH}$, and the egg mass oviposited by each tick was weighted and compared between test and control groups by Student's $t$ test $(P=0.05)$.

Engorged $R$. microplus and $R$. annulatus females were weighted and injected with $5 \mu \mathrm{l}$ of dsRNA $\left(5 \times 10^{10}\right.$ molecules per microliter) in the right spiracular plate within $6 \mathrm{~h}$ after dropping off the host using the same methods as described above or left uninjected. They were stored individually in an incubator at $22-25^{\circ} \mathrm{C}$ and $80 \% \mathrm{RH}$. Tick weight and egg masses removed after oviposition and weighted were analyzed as described above. Egg batches were stored separately under the same conditions to estimate percent hatching by counting the number unhatched eggs that was compared between test and control groups by $\chi^{2}$ test $(\alpha=0.01)$.

Ten ticks per group were dissected after oviposition and pooled for RNA extraction to evaluate gene expression by semiquantitative RT-PCR using the same oligonucleotide primers used for dsRNA synthesis. The messenger RNA (mRNA) levels (nanograms per amplicon) were estimated in ethidium bromide-stained agarose gels by comparison to a standard curve of the target gene and compared between target gene dsRNA and GIII dsRNA-injected control ticks to calculate the percent of gene silencing after RNAi.

Vaccine formulations $R$. microplus UBQ and SUB were produced for vaccination trials. Recombinant SUB was expressed in Escherichia coli from a synthetic gene (GenBank accession number GQ456170) optimized for codon usage in $E$. coli and purified by $\mathrm{Ni}$ affinity chromatography (Genscript Corporation, Piscatway, NJ, USA; www.genscript.com). The UBQ peptide NH2YNIQKESTLHLVLRLRGGMQIFVKTLTGKTITLEV EPSDTIENVKAKIQDKEGIPPDQQRLIF AGKQLED was synthesized and purified at the Bioanalytics, Pharmacology, and Proteomics facility (Barcelona Biomedical Research Park, Spain). The recombinant Bm86 (susceptible strain) used as positive control was secreted in Pichia pastoris and purified as reported previously (Canales et al. 2008). Protein adjuvation was made by mixing a solution of anhydromannitoletheroctodecenoate (Montanide ISA $50 \mathrm{~V}$; Seppic, Paris, France) with the recombinant protein solution in batch-by-batch processes using a high-speed mixer Heidolph DIAX 900 (Heidolph Elektro, Kelheim, Germany) at $8,000 \mathrm{rpm}$, and the vaccine was filled manually under sterile conditions in glass bottles of $20 \mathrm{ml}$ (Wheaton, Millville, NJ, USA) at a concentration of $100 \mu \mathrm{g} / 2 \mathrm{ml}$ dose. Quality controls were made by testing 
mechanical and thermal stability of vaccine emulsions as described previously (Canales et al. 1997).

Cattle immunization with recombinant proteins and tick infestations Four 1-year-old European crossbred calves per group were each immunized with three doses (weeks 1, 4, and 6) containing $100 \mu \mathrm{g}$ per dose of purified recombinant proteins formulated as described above. Negative controls were injected with adjuvant/saline alone. Cattle were injected intramuscularly with $2 \mathrm{ml} /$ dose using a $5-\mathrm{ml}$ syringe and an 18-gauge needle. Two weeks after the last immunization, cattle in vaccinated and control groups were infested with 10,000 R. annulatus (Mercedes, Texas, USA strain) and R. microplus (susceptible, Mexico strain) larvae/ animal applied individually to each animal in separate cotton cells attached to the back of the animals. Cattle were cared for in accordance with standards specified in the Guide for Care and Use of Laboratory Animals.

Data collection and evaluation Adult engorged female ticks dropping from cattle were daily collected, counted, and weighted. All the collected adult female ticks were assessed for oviposition and egg fertility (de la Fuente et al. 1999). The personnel collecting the ticks were "blinded" as to which group animals belonged. The efficacy of vaccine formulations was evaluated employing the following formulae (de la Fuente et al. 1999; Canales et al. 2009a).

Effect on the number of adult female ticks (DT) $=$ $100[1-(\mathrm{NTV} / \mathrm{NTC})]$, where NTV is the number of adult female ticks in the vaccinated group, and NTC is the number of adult female ticks in the control group.

Effect on tick weight $(\mathrm{DW})=100[1-(\mathrm{WTV} / \mathrm{WTC})]$, where WTV is the average adult female tick weight in the vaccinated group, and WTC is the average adult female tick weight in the control group.

Effect on oviposition $(\mathrm{DO})=100[1-(\mathrm{PATV} / \mathrm{PATC})]$, where PATV is the average weight of the eggs per survived tick in the vaccinated group, and PATC is the average weight of the eggs per survived tick in the control group.

Effect on egg fertility (DF) $=100[1-($ PPLOV $/$ PPLOC)], where PPLOV is the average weight of the larvae per gram of eggs in the vaccinated group, and PPLOC is the average weight of the larvae per gram of eggs in the control group.

Vaccine efficacy (E) was calculated as $100[1-(\mathrm{CRT} \times$ $\mathrm{CR} 0 \times \mathrm{CRF})]$, where $\mathrm{CRT}=\mathrm{NTV} / \mathrm{NTC}, \mathrm{CR} 0=\mathrm{PATV} /$ PATC, and CRF $=$ PPLOV/PPLOC that represent the reduction in the number of adult female ticks, oviposition, and egg fertility as compared to the control group, respectively.

A Student's $t$ test with unequal variance $(P=0.05)$ was used to compare the results of adult female tick number, tick weight, oviposition, and egg fertility between vaccinated and control groups.
Determination of serum antibody levels by enzyme-linked immunosorbent assay Before each immunization and 21 days after the last immunization, blood samples were collected from each calf into sterile tubes and maintained at $4^{\circ} \mathrm{C}$ until arrival at the laboratory. Serum was then separated after centrifugation and stored at $-20^{\circ} \mathrm{C}$. Serum antibody titers were determined using an antigen-specific indirect enzyme-linked immunosorbent assay (ELISA). Purified UBQ, SUB, and Bm86 (susceptible strain) antigens $(0.1 \mu \mathrm{g}$ per well) were used to coat ELISA plates overnight at $4^{\circ} \mathrm{C}$. Sera were serially diluted to $1: 10,1: 100$, and 1:1,000 in phosphate-buffered saline with Tween 20 (PBST; PBS $/ 0.5 \%$ Tween $20, \mathrm{pH} 7.2$ ) and $10 \%$ fetal bovine serum (Sigma). The plates were incubated with the diluted sera for $1 \mathrm{~h}$ at $37^{\circ} \mathrm{C}$ and then incubated with $1: 10,000$ rabbit antibovine immunoglubolin $\mathrm{G}(\mathrm{IgG})$-horseradish peroxidase conjugates (Sigma) for $1 \mathrm{~h}$ at $37^{\circ} \mathrm{C}$. The color reaction was developed with 3,3',5,5'- tetramethylbenzidine (Sigma), and the optical density $450 \mathrm{~nm}$ (OD) was determined. After incubation, the plates were washed with PBST. Antibody titers were considered positive when they yielded an $\mathrm{OD}_{450 \mathrm{~nm}}$ value at least twice as high as the preimmune serum. Antibody titers in immunized cattle were expressed as the $\mathrm{OD}_{450} \mathrm{~nm}$ value for the highest serum dilution $(1: 1,000)$ and compared between vaccinated and control cattle using an analysis of variance (ANOVA) test $(P<$ 0.05). Correlation analyses were conducted in Microsoft Excel to compare antibody titers at the time of tick infestation and vaccine efficacy calculated in individual cattle.

\section{Results and discussion}

The discovery and characterization of new tick-protective antigens is important to improve existing vaccines for the control of cattle tick infestations (de la Fuente et al. 2007a). However, the expenses and difficulties associated with the screening of tick-protective antigens and cattle vaccination trials constitute an obstacle toward this goal. Recently, RNAi has been proposed as a method for the rapid screening of tick-protective antigens (de la Fuente et al. 2005, 2007c). However, vaccination trials are ultimately needed to characterize new candidate tick-protective antigens.

In these experiments, RNAi was used to select the antigens for vaccination trials based on the effect of gene knockdown on cattle tick mortality, feeding, and fertility. The GST, UBQ, SEL, EF-1a, and SUB genes were selected for RNAi experiments in $R$. annulatus and/or $R$. microplus based on previous results in $R$. microplus or $D$. variabilis demonstrating an effect of gene knockdown on tick attachment, mortality, and/or fertility (de la Fuente et al. 2007b, 2008). The results showed that GST and SEL gene 
Table 1 Summary of RNAi experiments in unfed and engorged $R$. microplus female ticks

\begin{tabular}{|c|c|c|c|c|c|c|c|}
\hline \multirow[t]{2}{*}{ Parameter } & \multicolumn{7}{|c|}{ R. microplus cDNA group } \\
\hline & GST & UBQ & SEL & SUB & EF-1a & GIII & UNI \\
\hline \multicolumn{8}{|c|}{ Unfed female $R$. microplus } \\
\hline \multirow[t]{2}{*}{ Tick mortality $(\%)$} & 43 & $77^{*}$ & 50 & $73 *$ & $77 *$ & 53 & 27 \\
\hline & ND & $70 *$ & 53 & $67 *$ & $73 *$ & 53 & ND \\
\hline \multirow[t]{2}{*}{ Tick weight (mg) } & $214 \pm 115^{* *}$ & $85 \pm 129 * * *$ & $211 \pm 124 * *$ & $8 \pm 2 * * *$ & $55 \pm 140 * * *$ & $307 \pm 125$ & $485 \pm 113$ \\
\hline & ND & $227 \pm 95$ & $191 \pm 130^{* *}$ & $7 \pm 3 * * *$ & $4 \pm 5 * * *$ & $292 \pm 125$ & ND \\
\hline \multirow[t]{2}{*}{ Eggs/tick (mg) } & $80 \pm 60$ & $0 \pm 0 * * *$ & $59 \pm 64$ & $8 \pm 2 * *$ & $22 \pm 58$ & $26 \pm 39$ & $103 \pm 64$ \\
\hline & ND & $0 \pm 0 * * *$ & $121 \pm 43$ & $0 \pm 0 * * *$ & $0 \pm 0 * * *$ & $61 \pm 51$ & ND \\
\hline \multicolumn{8}{|c|}{ Engorged female $R$. microplus } \\
\hline Tick weight (mg) & $301 \pm 67$ & $314 \pm 18$ & $302 \pm 47$ & $284 \pm 45$ & $324 \pm 39$ & $364 \pm 22$ & $288 \pm 72$ \\
\hline Eggs/tick (mg) & $151 \pm 34$ & $89 \pm 30 * * *$ & $109 \pm 14^{* *}$ & $101 \pm 83$ & $123 \pm 89$ & $191 \pm 10$ & $158 \pm 46$ \\
\hline Egg hatching (\%) & 70 & $30 *$ & $30 *$ & $10^{*}$ & $5 *$ & 70 & 80 \\
\hline
\end{tabular}

Adult ticks ( $N=30$ for unfed and $N=3$ for engorged females) were injected with dsRNA or left uninjected (UNI). Two experiments were conducted in unfed ticks while a single experiment was done with engorged female ticks. Tick mortality and egg hatching are shown in percent and were compared to the GIII dsRNA-injected control ticks by $\chi 2$ test $\left({ }^{*} \alpha<0.01\right)$. Tick weight and oviposition (eggs per tick) are shown as average \pm SD and were compared to the GIII dsRNA-injected control ticks by Student's $t$ test $(* * P<0.05 ; * * * P<0.01)$

$N D$ not done, UNI uninjected

knockdown affected tick attachment $(60 \%$ and $65 \%$ tick attachment, respectively, when compared to $91 \%$ attachment in the controls; $\alpha<0.01)$ as in previous experiments with $D$. variabilis (de la Fuente et al. 2007b) but had no effect on $R$. microplus mortality and oviposition (Table 1) and were not characterized further. As in previous experiments (de la Fuente et al. 2007b, 2008), RNAi with UBQ, EF-1a, and SUB increased $R$. microplus mortality and reduced oviposition when compared to controls (Table 1). Despite the fact that gene expression was silenced between $75 \%$ and $100 \%$ in target gene dsRNA-injected R. microplus and $R$. annulatus ticks when compared to controls, in $R$. annulatus, only EF-1a knockdown had an effect on both tick mortality and oviposition (Table 2). However, tick-totick variations in RNAi results were higher in $R$. annulatus than in $R$. microplus probably because RNAi conditions are better established for $R$. microplus (Nijhof et al. 2007).
R. microplus UBQ, SUB, and EF-1a were selected for vaccination trials based on their effect on tick mortality and/ or oviposition after RNAi (Tables 1 and 2). However, recombinant EF-1a could not be produced in sufficient quantities for protein purification and vaccination trials were conducted with recombinant UBQ and SUB only in comparison with Bm86 (positive control) and adjuvant/ saline (negative control).

Except for cattle immunized with recombinant SUB, antibody titers in vaccinated cattle increased after successive immunizations (Fig. 1). However, anti-UBQ antibody titers in immunized cattle were not significantly different from control animals (Fig. 1). The poor immunogenicity of the UBQ vaccine could reflect self-tolerance to a highly conserved molecule in eukaryotes and the fact that short peptides are often not immunogenic and require conjugation to a carrier protein or the use of potent adjuvants to

Table 2 Summary of RNAi experiments in unfed $R$. annulatus female ticks

\begin{tabular}{|c|c|c|c|c|c|}
\hline \multirow[t]{2}{*}{ Parameter } & \multicolumn{5}{|c|}{ R. microplus cDNA group } \\
\hline & UBQ & SUB & EF-1a & GIII & UNI \\
\hline Tick mortality (\%) & $63^{*}$ & 47 & $90^{*}$ & 47 & 53 \\
\hline Tick weigh (mg) & $235 \pm 113$ & $69 \pm 86^{* * *}$ & $25 \pm 22 * * *$ & $206 \pm 108$ & $199 \pm 128$ \\
\hline Eggs/tick (mg) & $97 \pm 70$ & $70 \pm 83$ & $0 \pm 0 * * *$ & $114 \pm 56$ & $116 \pm 71$ \\
\hline Hatching (\%) & 80 & $20 *$ & $0^{*}$ & 100 & 90 \\
\hline
\end{tabular}

Adult unfed female ticks $(N=30)$ were injected with dsRNA or left uninjected (UNI). Tick mortality and egg hatching are shown in percent and were compared to the GIII dsRNA-injected control ticks by $\chi^{2}$ test $(* \alpha<0.01)$. Tick weight and oviposition (eggs per tick) are shown as average \pm $\mathrm{SD}$ and were compared to the GIII dsRNA-injected control ticks by Student's $t$ test $(* * P<0.05 ; * * * P<0.01)$

UNI uninjected 


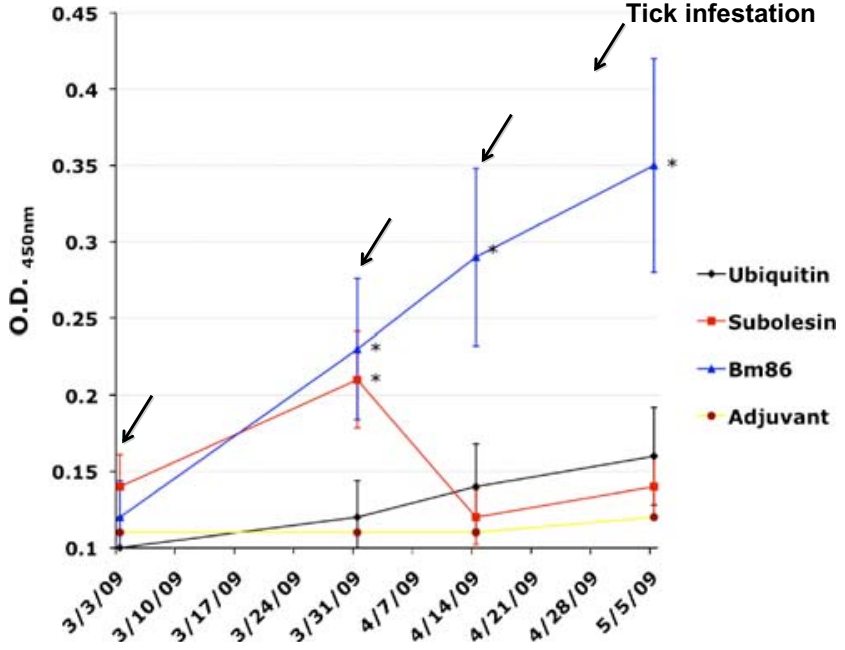

Fig. 1 Antibody response in vaccinated cattle. Bovine serum antibody titers to recombinant antigens were determined by ELISA in cattle vaccinated with ubiquitin, subolesin, Bm86, and adjuvant/ saline control. Antibody titers in immunized cattle were expressed as the $\mathrm{OD}_{450 \mathrm{~nm}}$ value for the highest serum dilution $(1: 1,000)$ and compared between vaccinated and control cattle using an ANOVA test $\left({ }^{*} P<0.05\right)$. The time of vaccination shots (arrows) and tick infestation are indicated

increase immunogenicity (Rodríguez et al. 1994; Haro and Gómara 2004). In cattle immunized with recombinant SUB, antibody titers increased after the first immunization and then decreased after the second immunization (Fig. 1). The cause for this decrease in anti-SUB antibody titers after the second immunization is unknown but could be due to problems associated with the stability of the vaccine formulation. The vaccine containing the recombinant
Bm86 antigen in Montanide ISA $50 \mathrm{~V}$ has been shown to be stable even at field temperature (Canales et al. 2007 and unpublished results), but vaccine stability could be different for different antigen preparations. In general, antibody titers were low in immunized cattle, even in the animals vaccinated with the control $\mathrm{Bm} 86$ vaccine when compared to previous studies (Canales et al. 2009a). Although cattle were apparently healthy, low antibody responses after vaccination suggested that animals were probably not in the best health condition. Nevertheless, a positive correlation (correlation coefficients $R^{2}=0.7,0.8$, and 0.9 in UBQ-, SUB-, and Bm86-immunized cattle, respectively) between antibody titers 1 week after tick infestation and vaccine efficacy calculated in individual cattle was obtained for R. microplus. For $R$. annulatus, a positive correlation $\left(R^{2}=\right.$ $0.6)$ between antibody titers and vaccine efficacy was obtained in SUB-immunized cattle only. A positive correlation between antibody titers and vaccine efficacy has been previously demonstrated in Bm86-vaccinated cattle and underlines the effect of antitick vaccines on the control of cattle tick infestations (Cobon et al. 1995; de la Fuente et al. 1998).

The results of the vaccine trial showed an effect on $R$. microplus and $R$. annulatus infestations for all three antigens when compared to controls (Tables 3 and 4). The efficacy with the $\mathrm{Bm} 86$ vaccine were within the range reported in previous experiments (Cobon et al. 1995; Fragoso et al. 1998; de la Fuente et al. 1998, 1999, 2000a, b; García-García et al. 2000; de Vos et al. 2001; de la Fuente and Kocan 2003, 2006; Canales et al. 2009a) and was higher than that obtained with UBQ and SUB vaccines

Table 3 Control of $R$. microplus infestations in cattle vaccinated with the recombinant antigens

R. microplus (susceptible; Mexico strain)

Percent reduction $\left(\right.$ vaccinated/control) ${ }^{\mathrm{b}}$

$\mathrm{E}^{\mathrm{c}}$

\begin{tabular}{|c|c|c|c|c|c|}
\hline Experimental group $^{\mathrm{a}}$ & DT & DW & DO & DF & \\
\hline \multirow[t]{2}{*}{ Ubiquitin } & $26 \%$ & $9 \%$ & $-2 \%$ & $29 \%$ & $55 \%$ \\
\hline & $(1,079 \pm 410)$ & $(251 \pm 52)$ & $(109 \pm 9)$ & $(0.37 \pm 0.04)$ & \\
\hline \multirow[t]{2}{*}{ Subolesin } & $43 \%$ & $0 \%$ & $0 \%$ & $15 \%$ & $51 \%$ \\
\hline & $(835 \pm 179)^{*}$ & $(277 \pm 33)$ & $(107 \pm 21)$ & $(0.44 \pm 0.06)$ & \\
\hline \multirow[t]{2}{*}{ Bm86 } & $51 \%$ & $5 \%$ & $14 \%$ & $6 \%$ & $60 \%$ \\
\hline & $(714 \pm 208)^{*}$ & $(261 \pm 26)$ & $(92 \pm 16)$ & $(0.49 \pm 0.04)$ & \\
\hline Adjuvant/saline control & $(1,454 \pm 206)$ & $(276 \pm 14)$ & $(107 \pm 12)$ & $(0.52 \pm 0.29)$ & - \\
\hline
\end{tabular}

$D T$ percentage reduction in tick infestation, $D W$ percentage reduction in tick weight, $D O$ percentage reduction in oviposition, $D F$ percentage reduction in egg fertility

${ }^{a}$ Cattle were randomly assigned to experimental groups $(N=4)$, vaccinated, and challenged with $R$. microplus and $R$. annulatus larvae

${ }^{\mathrm{b}}$ The percent reduction was calculated with respect to the control group. In parenthesis are shown the average \pm SD for adult female tick number, tick weight (milligram), oviposition (egg weight (milligram) per tick), and egg fertility (larvae weight per egg weight) and were compared by Student's $t$ test with unequal variance between vaccinated and control groups $(* P<0.05)$

${ }^{\mathrm{c}}$ Vaccine efficacy $(\mathrm{E})$ was calculated as $100[1-(\mathrm{CRT} \times \mathrm{CR} 0 \times \mathrm{CRF})]$, where CRT, CRO, and CRF are the reduction in the number of adult female ticks, oviposition, and egg fertility as compared to the control group, respectively 
Table 4 Control of $R$. annulatus infestations in cattle vaccinated with the recombinant antigens

\begin{tabular}{|c|c|c|c|c|c|}
\hline \multirow[b]{3}{*}{ Experimental group $^{\mathrm{a}}$} & \multicolumn{5}{|c|}{ R. annulatus (Mission, TX strain) } \\
\hline & \multicolumn{4}{|c|}{ Percent reduction (vaccinated/control) ${ }^{\mathrm{b}}$} & \multirow[t]{2}{*}{$E^{c}$} \\
\hline & DT & DW & DO & $\mathrm{DF}$ & \\
\hline Ubiquitin & $\begin{array}{l}-2 \% \\
(519 \pm 96)\end{array}$ & $\begin{array}{l}-19 \% \\
(275 \pm 29)\end{array}$ & $\begin{array}{l}-21 \% \\
(109 \pm 15)\end{array}$ & $\begin{array}{l}15 \% \\
(0.13 \pm 0.03)\end{array}$ & $15 \%$ \\
\hline Subolesin & $\begin{array}{l}18 \% \\
(419 \pm 288)\end{array}$ & $\begin{array}{l}17 \% \\
(192 \pm 129)\end{array}$ & $\begin{array}{l}23 \% \\
(69 \pm 49)\end{array}$ & $\begin{array}{l}37 \% \\
(0.09 \pm 0.07)\end{array}$ & $60 \%$ \\
\hline Bm86 & $\begin{array}{l}100 \% \\
(0 \pm 0)^{*}\end{array}$ & $\begin{array}{l}\text { All ticks } \\
\text { Died }\end{array}$ & $\begin{array}{l}\text { All ticks } \\
\text { Died }\end{array}$ & $\begin{array}{l}\text { All ticks } \\
\text { Died }\end{array}$ & $100 \%$ \\
\hline Adjuvant/saline control & $(509 \pm 145)$ & $(231 \pm 28)$ & $(90 \pm 20)$ & $(0.15 \pm 0.03)$ & - \\
\hline
\end{tabular}

$D T$ percentage reduction in tick infestation, $D W$ percentage reduction in tick weight, $D O$ percentage reduction in oviposition, $D F$ percentage reduction in egg fertility

${ }^{a}$ Cattle were randomly assigned to experimental groups $(N=4)$, vaccinated, and challenged with $R$. microplus and $R$. annulatus larvae

${ }^{\mathrm{b}}$ The percent reduction was calculated with respect to the control group. In parenthesis are shown the average \pm SD for adult female tick number, tick weight (milligram), oviposition (egg weight (milligram) per tick) and egg fertility (larvae weight per egg weight) and were compared by Student's $t$ test with unequal variance between vaccinated and control groups $\left({ }^{*} P<0.05\right)$

${ }^{\mathrm{c}}$ Vaccine efficacy $(\mathrm{E})$ was calculated as $100[1-(\mathrm{CRT} \times \mathrm{CR} 0 \times \mathrm{CRF})]$, where CRT, CRO, and CRF are the reduction in the number of adult female ticks, oviposition, and egg fertility as compared to the control group, respectively

in both tick species. Particularly for $R$. annulatus control, it is difficult to improve the results obtained with Bm86 vaccines which attain $>99 \%$ efficacy in all experiments (Fragoso et al. 1998; de la Fuente et al. 2000a, b; de Vos et al. 2001; Canales et al. 2009a). For SUB, this is the first vaccination trial in $R$. microplus and $R$. annulatus, and the results were similar to those reported in other tick species (Almazán et al. 2005a, b; de la Fuente et al. 2006; Canales et al. 2009b) and support further experiments with this antigen. Vaccination with the UBQ peptide had some efficacy on tick control, particularly on $R$. microplus infestations (Table 3). However, these results were affected by the low immunogenicity of the UBQ vaccine preparation and require additional trials with improved peptide formulations before a conclusion could be reached.

The genes were selected for vaccination trials based on their effect on tick mortality and fertility after RNAi experiments included those encoding for proteins involved in the regulation of mRNA and protein synthesis and metabolism with potential impact on important biological processes in eukaryotes such as cell growth and maintenance. However, these proteins are cytoplasmic and may be evolutionary highly conserved which may pose a problem for their use in vaccine formulations for the control of tick infestations. As previously discussed, the conservation of protein ortholog sequences among arthropod vectors and vertebrate hosts may raise the question of safety when using them for immunization with the potential of inducing autoimmune responses damaging to the host (Canales et al. 2009b). However, it is expected that the antibody response would be primarily directed against nonself epitopes thus reducing the possibility of detrimental effects to the host. Additionally, immunization with intracellular proteins has been effective in ticks and other invertebrate organisms and suggests a low risk to induce autoimmune responses in vertebrate hosts (Elad and Segal 1995; Almazán et al. 2005a, b; de la Fuente et al. 2006; Canales et al. 2009b).

In summary, these experiments showed that RNAi could be used for the selection of candidate tick-protective antigens. However, vaccination trials are necessary to evaluate the effect of recombinant antigens in the control of tick infestations, a process that requires efficient recombinant protein production and formulation systems. The results with the SUB vaccine encourage further investigations on the use of recombinant subolesin alone or in combination with other antigens for the control of cattle tick infestations.

Acknowledgments We thank Alejandro González, Vladimir Guerrero, Urbano Martínez, and Uriel Valdez (Universidad Autónoma de Tamaulipas, Mexico) for technical assistance. This work was supported by the Wellcome Trust under the Animal Health in the Developing World initiative through project 0757990 entitled "Adapting recombinant antitick vaccines to livestock in Africa"; SEP-CONACYT, Mexico (project 25772); FOMIX, Tamaulipas, Mexico (project 73622); INIA, Spain (project FAU2008-00014-00-00); the Consejería de Educación y Ciencia, JCCM, Spain (project PAI06-0046-5285) and was facilitated through the Integrated Consortium on Ticks and Tick-borne Diseases (ICTTD-3), financed by the International Cooperation Program of the European Union, coordination action project no. 510561. M. Villar was funded by the JAE-DOC program (CSIC-FSE), Spain. 
Open Access This article is distributed under the terms of the Creative Commons Attribution Noncommercial License which permits any noncommercial use, distribution, and reproduction in any medium, provided the original author(s) and source are credited.

\section{References}

Almazán C, Blas-Machado U, Kocan KM, Yoshioka JH, Blouin EF, Mangold AJ, de la Fuente J (2005a) Characterization of three Ixodes scapularis cDNAs protective against tick infestations. Vaccine 23:4403-4416

Almazán C, Kocan KM, Blouin EF, de la Fuente J (2005b) Vaccination with recombinant tick antigens for the control of Ixodes scapularis adult infestations. Vaccine 23:5294-5298

Barker SC, Murrell A (2004) Systematics and evolution of ticks with a list of valid genus and species names. Parasitol 129:S15S36

Canales M, Enriquez A, Ramos E, Cabrera D, Dandie H, Soto A, Falcon V, Rodríguez M, de la Fuente J (1997) Large-scale production in Pichia pastoris of the recombinant vaccine Gavac $^{\mathrm{TM}}$ against cattle ticks. Vaccine 15:414-422

Canales M, Pérez de la Lastra JM, Naranjo V, Nijhof AM, Hope M, Jongejan F, de la Fuente J (2008) Expression of recombinant Rhipicephalus (Boophilus) microplus, R. annulatus and $R$. decoloratus $\mathrm{Bm} 86$ orthologs as secreted proteins in Pichia pastoris. BMC Biotechnol 8:14

Canales M, Almazán C, Naranjo V, Jongejan F, de la Fuente J (2009a) Vaccination with recombinant Boophilus annulatus Bm86 ortholog protein, $\mathrm{Ba} 86$, protects cattle against $B$. annulatus and $B$. microplus infestations. BMC Biotechnol 9:29

Canales M, Naranjo V, Almazán C, Molina R, Tsuruta SA, Szabó MPJ, Manzano-Roman R, Pérez de la Lastra JM, Kocan KM, Jiménez MI, Lucientes J, Villar M, de la Fuente J (2009b) Conservation and immunogenicity of the mosquito ortholog of the tick protective antigen, subolesin. Parasitol Res 105:97-111

Cobon G, Hungerford J, Woodrow M, Smith D, Willadsen P (1995) Vaccination against Boophilus microplus. The Australian field experience. In: de la Fuente J (ed) Recombinant vaccines for the control of cattle tick. Elfos Scientiae, La Habana, Cuba, pp 163176

de la Fuente J, Kocan KM (2003) Advances in the identification and characterization of protective antigens for development of recombinant vaccines against tick infestations. Expert Rev Vaccines 2:583-593

de la Fuente J, Kocan KM (2006) Strategies for development of vaccines for control of ixodid tick species. Parasite Immunol 28:275-283

de la Fuente J, Rodríguez M, Redondo M, Montero C, García-García JC, Méndez L, Serrano E, Valdés M, Enríquez A, Canales M, Ramos E, de Armas CA, Rey S, Rodríguez JL, Artiles M, García L (1998) Field studies and cost-effectiveness analysis of vaccination with Gavac ${ }^{\mathrm{TM}}$ against the cattle tick Boophilus microplus. Vaccine 16:366-373

de la Fuente J, Rodríguez M, Montero C, Redondo M, García-García JC, Méndez L, Serrano E, Valdés M, Enríquez A, Canales M, Ramos E, Boué O, Machado H, Lleonart R (1999) Vaccination against ticks (Boophilus spp.): the experience with the Bm86-based vaccine Gavac ${ }^{\mathrm{TM}}$. Genetic Analysis: Biomolecular Engineering 15:143-148

de la Fuente J, Rodríguez M, Garcia-Garcia JC (2000a) Immunological control of ticks through vaccination with Boophilus microplus gut antigens. Ann NY Acad Sci 916:617-621 de la Fuente J, García-García JC, González DM, Izquierdo G, Ochagavia ME (2000b) Molecular analysis of Boophilus spp. (Acari: Ixodidae) tick strains. Vet Parasitol 92:209-222

de la Fuente J, Almazán C, Blouin EF, Naranjo V, Kocan KM (2005) RNA interference screening in ticks for identification of protective antigens. Parasitol Res 96:137-141

de la Fuente J, Almazán C, Blas-Machado U, Naranjo V, Mangold AJ, Blouin EF, Gortazar C, Kocan KM (2006) The tick protective antigen, 4D8, is a conserved protein involved in modulation of tick blood ingestion and reproduction. Vaccine 24:4082-4095

de la Fuente J, Almazán C, Canales M, Pérez de la Lastra JM, Kocan KM, Willadsen P (2007a) A ten-year review of commercial vaccine performance for control of tick infestations on cattle. Anim Health Res Rev 8:23-28

de la Fuente J, Blouin EF, Manzano-Roman R, Naranjo V, Almazán C, Perez de la Lastra JM, Zivkovic Z, Jongejan F, Kocan KM (2007b) Functional genomic studies of tick cells in response to infection with the cattle pathogen, Anaplasma marginale. Genomics 90:712-722

de la Fuente J, Kocan KM, Almazán C, Blouin EF (2007c) RNA interference for the study and genetic manipulation of ticks. Trends Parasitol 23:427-433

de la Fuente J, Maritz-Olivier C, Naranjo V, Ayoubi P, Nijhof AM, Almazán C, Canales M, Pérez de la Lastra JM, Galindo RC, Blouin EF, Gortazar C, Jongejan F, Kocan KM (2008) Evidence of the role of tick subolesin in gene expression. BMC Genomics 9:372

de Vos S, Zeinstra L, Taoufik O, Willadsen P, Jongejan F (2001) Evidence for the utility of the Bm86 antigen from Boophilus microplus in vaccination against other tick species. Exp Appl Acarol 25:245-261

Elad D, Segal E (1995) Immunogenicity in calves of a crude ribosomal fraction of Trichophyton verrucosum: a field trial. Vaccine 13:83-87

Estrada-Peña A, Bouattour A, Camicas JL, Guglielmone A, Horak I, Jongejan F, Latif A, Pegram R, Walker AR (2006) The known distribution and ecological preferences of the tick subgenus Boophilus (Acari: Ixodidae) in Africa and Latin America. Exp Appl Acarol 38:219-235

Fragoso H, Hoshmand Rad P, Ortiz M, Rodríguez M, Redondo M, Herrera L, de la Fuente J (1998) Protection against Boophilus annulatus infestations in cattle vaccinated with the B. microplus Bm86-containing vaccine Gavac. Vaccine 16:1990-1992

García-García JC, González IL, González DM, Valdés M, Méndez L, Lamberti J, D'Agostino B, Citroni D, Fragoso H, Ortiz M, Rodríguez M, de la Fuente J (1999) Sequence variations in the Boophilus microplus Bm86 locus and implications for immunoprotection in cattle vaccinated with this antigen. Exp Appl Acarol 23:883-895

García-García JC, Montero C, Redondo M, Vargas M, Canales M, Boué O, Rodríguez M, Joglar M, Machado H, González IL, Valdés M, Méndez L, de la Fuente J (2000) Control of ticks resistant to immunization with $\mathrm{Bm} 86$ in cattle vaccinated with the recombinant antigen $\mathrm{Bm} 95$ isolated from the cattle tick, Boophilus microplus. Vaccine 18:2275-2287

Graf JF, Gogolewski R, Leach-Bing N, Sabatini GA, Molento MB, Bordin EL, Arantes GJ (2004) Tick control: an industry point of view. Parasitol 129:S427-S442

Haro I, Gómara MJ (2004) Design of synthetic peptidic constructs for the vaccine development against viral infections. Curr Protein Pept Sci 5:425-433

Nijhof AM, Taoufik A, de la Fuente J, Kocan KM, de Vries E, Jongejan F (2007) Gene silencing of the tick protective antigens, Bm86, Bm91 and subolesin, in the one-host tick Boophilus microplus by RNA interference. Int J Parasitol 37:653-662 
Olwoch JM, Van Jaarsveld AS, Scholtz CH, Horak IG (2007) Climate change and the genus Rhipicephalus (Acari: Ixodidae) in Africa. Onderstepoort J Vet Res 74:45-72

Peter RJ, Van den Bossche P, Penzhorn BL, Sharp B (2005) Tick, fly, and mosquito control-lessons from the past, solutions for the future. Vet Parasitol 132:205-215

Rand KN, Moore T, Sriskantha A, Spring K, Tellam R, Willadsen P, Cobon G (1989) Cloning and expression of a protective antigen from the cattle tick Boophilus microplus. Proc Natl Acad Sci USA 86:9657-9661

Rodríguez M, Rubiera R, Montesinos R, Cremata JA, Falcón V, Sanchez G, Bringas R, Cordovés C, Valdés M, Lleonart R, Herrera L, de la Fuente J (1994) High level expression of the $B$. microplus $\mathrm{Bm} 86$ antigen in the yeast $P$. pastoris forming highly immunogenic particles for cattle. J Biotechnol 33:135-146

Rodríguez Valle M, Méndez L, Valdez M, Redondo M, Espinosa CM, Vargas M, Cruz RL, Barrios HP, Seoane G, Ramírez ES, Boué O,
Vigil JL, Machado H, Nordelo CB, Piñeiro MJ (2004) Integrated control of Boophilus microplus ticks in Cuba based on vaccination with the anti-tick vaccine Gavac. Exp Appl Acarol 34:375-382

Sonenshine DE, Kocan KM, de la Fuente J (2006) Tick control: further thoughts on a research agenda. Trends Parasitol 22:550-551

Sossai S, Peconick AP, Sales-Junior PA, Marcelino FC, Vargas MI, Neves ES, Patarroyo JH (2005) Polymorphism of the bm86 gene in South American strains of the cattle tick Boophilus microplus. Exp Appl Acarol 37:199-214

Willadsen P (2006) Tick control: thoughts on a research agenda. Vet Parasitol 138:161-168

Willadsen P, Riding GA, McKenna RV, Kemp DH, Tellam RL, Nielsen JN, Lahstein J, Cobon GS, Gough JM (1989) Immunological control of a parasitic arthropod: identification of a protective antigen from Boophilus microplus. J Immunol 143:1346-1351 